PACS 64.70.pe

\title{
On plastic deformation of bulk metallic glasses in Bridgman anvils
}

\author{
G.F. Korznikova ${ }^{1 \dagger}$, T.H. Czeppe ${ }^{2}$, A.V. Korznikov ${ }^{1}$ \\ †korznikova@anrb.ru \\ ${ }^{1}$ Institute for Metals Superplasticity Problems RAS, Khalturin St. 39, 450001, Ufa, Russia \\ ${ }^{2}$ Institute of Metallurgy and Materials Science PAS, Reymonta St. 25, 30-059, Krakow, Poland
}

The paper demonstrates the possibility, in principle, of plastic deformation of bulk metallic Ti- and Zr-based glasses with a fully amorphous structure using a method of severe deformation in a copper shell in Bridgman's anvils. The presence in the structure of the crystalline phase inclusions in the form of a pile-up of lamellae leads to embrittlement of metallic glass.

Key words: bulk metallic glasses, high-pressure torsion.

\section{Introduction}

The unique properties of amorphous materials, such as a low Young's modulus, high strength, hardness and corrosion resistance, attracted the attention of researchers for several dozens of years [1-3]. However, the possibility of their practical use was limited by the small thickness (usually, 10-50 $\mu \mathrm{m}$ ) and a rather low thermal stability of amorphous alloys. The bulk metallic Ti- and Zr-based glasses produced relatively recently in the form of rods with a diameter of several millimeters may have a practical application, including one in traumatology and orthopedic surgery. Presently it is predominantly commercial Ti-based alloy (Ti-6Al-4V, Ti-6Al-7Nb, Ti-5Al-2.5Fe) that are used for making implants. One of the main problems of such implants is the discrepancy between Young's modulus values $(E)$ of a bone $(E=10-30 \mathrm{GPa})$ and of an implant $(E=110-120 \mathrm{GPa}$ for commercially pure Ti and its alloys) $[1,4]$, which causes an insufficient loading and a gradual destruction of bone tissues adjacent to the implant. An additional factor that reduces biocompatibility is precipitation of toxic metal ions and/or of their particles due to corrosion and wear, which may lead to inflammatory processes. Therefore many researchers focus their efforts on development of novel Ti alloys with improved biomechanical characteristics. An alternative for commercial titanium alloys could be bulk Ti-based metallic glasses since the mechanical characteristics of these materials match better than the characteristics of bone tissue. In particular, bulk glasses that do not contain toxic or non-biocompatible elements such as $\mathrm{Be}, \mathrm{Al}, \mathrm{Ni}, \mathrm{Co}$ or $\mathrm{Cr}$ [3], possess higher strength, a low Young's modulus and often a better wear resistance and corrosion resistance than their crystalline counterparts [2]. Besides, as was demonstrated "in vitro", Ti- or Zr-based metallic glasses can support adhesion and growth of grains, which allows to view them as promising materials for various types of implants $[5,6]$. However, fully amorphous glasses, possessing an ultimate strength of 1-2 GPa [2], in the absence of dislocations deform as a result of generation and proliferation of shear bands. Individual localized bands may intersect throughout the sample, which is the reason for an extreme brittleness of amorphous ribbons under tension and upsetting. Of key importance is the issue of fracture toughness enhancement of these high-strength materials [1]. One of the new approaches to overcome the catastrophic brittleness of glasses is creation of a composite material with an amorphous matrix and disperse crystalline inclusions which provide for deceleration of the initial shear bands, thus stimulating formation of a multitude of new shear bands, which results in delocalization of high internal stresses and an increase in fracture toughness [7]. Yet another direction aimed at plasticization of amorphous materials is formation of a gradient structure with a smooth transition from an amorphous structure to a crystalline one, as a result of severe deformation, for instance, by ball milling [8]. We demonstrated earlier that severe deformation in Bridgman's anvils could be used for consolidation of amorphous Ni-based ribbons and fabrication of monolithic amorphous samples [9-12].

The aim of the present work is to study the possibility in principle to realize plastic deformation of bulk metallic Tiand Zr-based glasses using the severe plastic deformation method in a copper shell in Bridgman's anvils. Three alloys were studied for comparison, two of which were fully amorphous, and one contained inclusions of the crystalline phase in the form of pile-ups of the lamellar phase. Alloys with a similar composition are distinguished by a high glass-forming ability [13]. It is supposed that they can be used as fixation elements for osteosynthesis that work in the conditions of complex loading.

\section{The material and the methods of investigation}

Bulk metallic glasses (BMG) of three compositions were selected for the study: $\mathrm{Ti}_{40} \mathrm{Cu}_{40} \mathrm{Pd}_{10} \mathrm{Zr}_{10}$ (Pd-10), $\mathrm{Ti}_{40} \mathrm{Cu}_{36} \mathrm{Pd}_{14} \mathrm{Zr}_{10}(\mathrm{Pd}-14)$ and $\mathrm{Ti}_{40} \mathrm{Cu}_{30} \mathrm{Pd}_{20} \mathrm{Zr}_{10}(\mathrm{Pd}-20)$. The alloys were prepared from high-purity components using the levitation method in argon medium [14]. Bulk amorphous bars with a diameter of $2.8 \mathrm{~mm}$ were cast into a copper mould which was cooled. Then the bars were cut into parts with a length of $2 \mathrm{~mm}$ and inserted into a copper disk with 


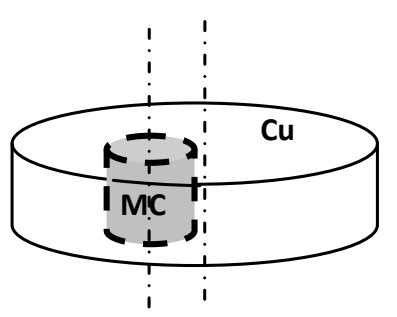

Fig. 1. Scheme of an initial sample consisting of a copper matrix and an insert of metallic glass (MG).

a diameter of $10 \mathrm{~mm}$ and a thickness of $2 \mathrm{~mm}$, at a distance of $1 \mathrm{~mm}$ from the sample center (fig.1). The obtained composed samples were deformed by high-pressure torsion in Bridgman's anvils under a pressure of $6 \mathrm{GPa}$ until $\mathrm{n}=5$ revolutions. After the deformation, the samples had a lens shape with a maximum thickness around $0.5 \mathrm{~mm}$.

Analysis of the cross section of the samples after torsion in Bridgman's anvils was conducted on a TESCAN LIRA3 scanning electron microscope. Chemical composition was monitored using the method of energy-dispersive analysis on a TESCAN VEGA 3SBH scanning electron microscope. EBSD analysis was performed on a Tescan Mira 3LMH scanning electron microscope using an OXFORD HKL Channel 5 microanalysis system. Imaging was done at intervals of 0.2 $\mu \mathrm{m}$.

Differential scanning calorimetry (DSC) was performed on a TA DSC Q1000 calorimeter with continuous heating at a rate of $20 \mathrm{~K} / \mathrm{s}$.

\section{Results and discussion}

According to the data from X-ray structural analysis, the initial samples of Pd-10 and Pd-14 had a fully amorphous structure, while the sample of $\mathrm{Pd}-20$ contained inclusions of the crystalline phase [15]. These data confirm the results of DSC. Figure 2 presents experimental DSC curves for all of the three alloys under investigation. It has been shown that the exothermic peaks refer to the processes of crystallization, and the temperature of crystallization initiation grows with an increase in the content of Pd [15]. The presence of several peaks is connected with the multi-stage character of crystallization. On the curves corresponding to Pd-10 and Pd-14 the exothermic peaks are more pronounced, while for the

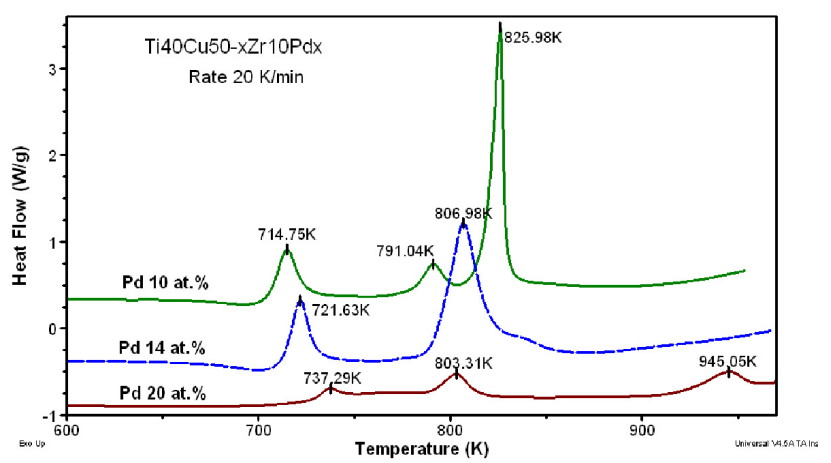

Fig. 2. DSC curves for bulk metallic glasses in the initial state. The heating rate is $20 \mathrm{~K} / \mathrm{min}$ [15].
Pd-20 composition the peaks are less clear due to a partial structure crystallization in the initial state.

Figure $3 a, b$ and $c$, shows the cross sections of the samples after various strain degrees. It can be seen that the composed samples have not lost their continuity (have not fractured) both at small and at large strains, whereas the samples thickness has fallen by several times. All the samples have acquired a lens shape. In spite of such a significant deformation, no cracks or ruptures indicating initiation of the fracture process, have been observed inside the inserts of metallic glasses Pd-10 and Pd-14 (fig.3).

The shape of the amorphous inserts of Pd-10 and Pd-14 varied depending on strain. At low rpm of the moveable anvil $(\varphi \leq \pi)$, the metallic glass insert remained integral and was restricted by the copper shell only in the thin near-surface layer and at the periphery of the samples. The interface in these cases was predominantly smooth from the side of the stationary anvil and wave-like from the side of the moveable anvil. At a large strain $(\varphi=10 \pi)$ all the interfaces were predominantly smooth. Analysis of chemical composition showed the absence of a noticeable redistribution of chemical elements in the vicinity of flat and wavy interfaces and a uniform distribution of elements in the amorphous phase (fig.4).

Earlier, using a method of modeling (finite element analysis), forming, flow character and stress-strained state parameters of ingots subjected to high-pressure torsion under a load were studied $[16,17]$. It was demonstrated that in the initial stage of deformation there was observed an intensive slip of metal along the surface under the rotating head. The quantitative and qualitative estimate of distribution of accumulated strain and flow stress intensities in the near-contact zones showed that near the surface close to the moveable head, accumulated strain reached its maximum, while near the surface close to the stationary head, accumulated strain decreased [17]. As the number of revolutions increased, deformation propagated from the surface into the depth of the sample. The results presented in [16, 17], obtained by mod-

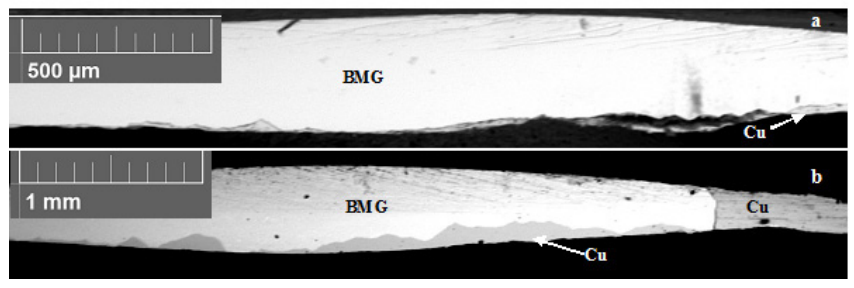

Fig. 3. Cross section of samples with an insert of Pd-14 after straining $\varphi=10 \pi(\mathrm{a})$ and $\varphi=\pi(\mathrm{b})$. The bright part is the metallic glass.

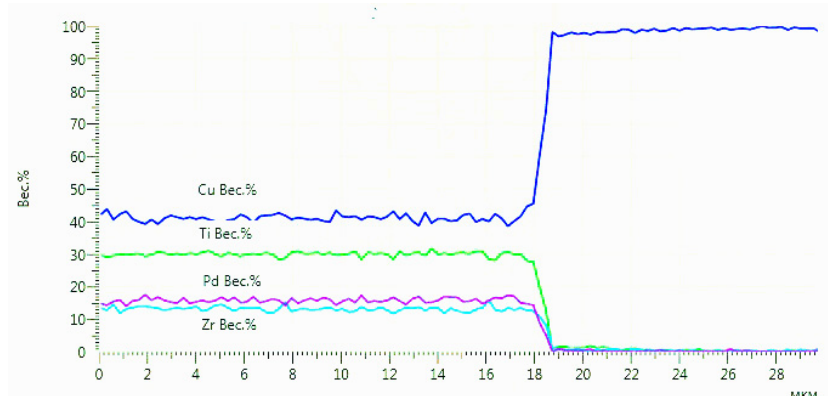

Fig. 4 Distribution of chemical elements near the interface in a sample with Pd-10 after straining $\varphi=2 \pi$. 


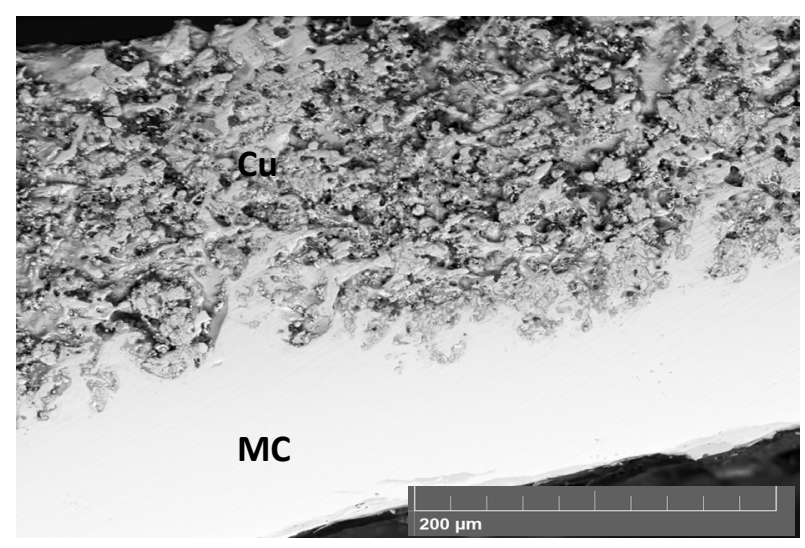

Fig. 5. Microstructure of the cross section of a sample with an insert of BG Pd-10 after straining $\varphi=2 \pi$.

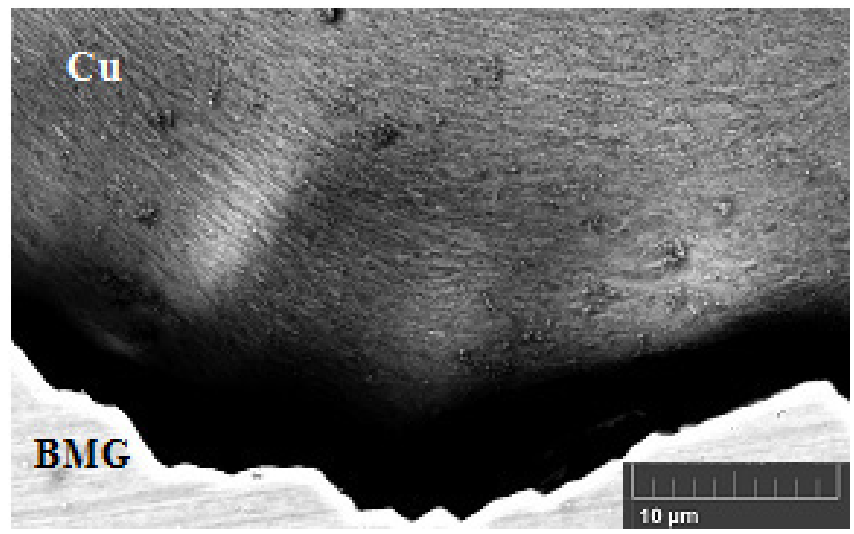

Fig. 6. Microstructure of the cross section of a sample with an insert of MG Pd-10 after straining $\varphi=2 \pi$. The regime of BSE.

eling, were confirmed by full-scale experiments on the alloy $25 \mathrm{Kh} 15 \mathrm{~K}[18]$.

At the same time, at the strain $\varphi \sim 2 \pi$ in the Pd- 10 samples, alongside with flat interfaces, wave-like traces of mixing of the amorphous material with the copper matrix were observed (fig.5), however, the insert did not fracture and remained integral. The mixing evidently takes place as a result of action of pressure, shear components, turning moments of stresses, friction of surfaces. Similar wave-like non-uniformities of interface were observed in the work [19] at some regimes of explosion welding.

In the vicinity of the wave-like interface between $\mathrm{Cu}$ and MG, in the copper matrix there appears a metallographic texture which can be well seen in the image made in the regime of back-scattered electrons (BSE) (fig.6). It is visible that as a result of deformation, not only has the shape of the amorphous insert changed, but the copper grain size has also decreased to $0.3 \mu \mathrm{m}$ in the cross section. Diffraction (EBSD) analysis has shown that the boundaries that have formed in the copper matrix are predominantly high-angle, and the metallic glasses remain amorphous after deformation.

Another character of interfaces is observed in the Pd-20 samples with an initial amorphous-crystalline structure. At a small strain $(\varphi=0.5 \pi)$, the insert remained integral, but with a growing strain, the insert got separated into individual large and small fragments. Here, at the periphery of the Pd-20 samples where true strain was maximum, small tear-outs of the metallic glass into the copper matrix are observed. As a result, there forms an inhomogenuous composite
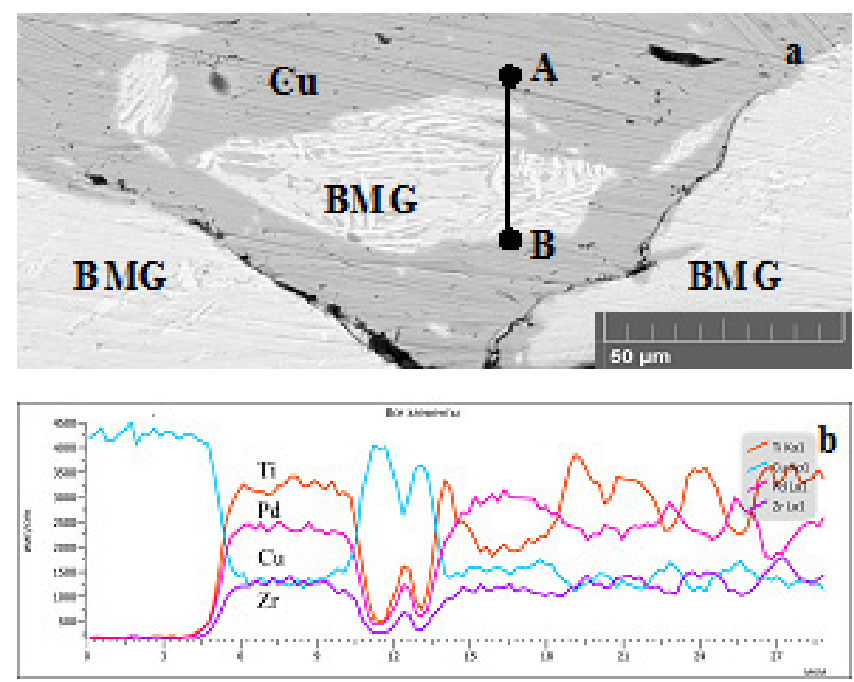

Fig. 7. Microstructure of the cross section of a sample with an insert of BG Pd-20 after straining $\varphi=4 \pi$ in the center (a) and distribution of chemical elements along the line $\mathrm{AB}$ in the lamellar pile-up in fig.7a (b).

structure consisting of large and small MG particles of the incorrect shape in the copper matrix with a submicrocrystalline structure (fig.7a). An electron microprobe analysis of an MG fragment along the $\mathrm{AB}$ section indicated in fig.7a is presented in fig.7b. The lamellar character of the interior structure and the distribution of chemical elements across the fragment section indicate that the fragment has a crystalline structure.

Note should be made that the main part of the small fragments has the same lamellar structure. The same pile-ups of lamellae are visible inside the large MG fragments of the Pd-20 composition after deformation, and have been revealed in the initial MGs of the Pd-20 composition prior to deformation. Thus, the main reason for brittleness of Pd-20 MGs is evidently the presence of lamellar crystalline inclusions in the amorphous matrix.

\section{Conclusions}

1. Straining in a copper shell in Bridgman's anvils allows to effect plastic deformation of samples made of bulk metallic glasses with a fully amorphous structure without their fracture.

2. In the case of fully amorphous metallic glasses, crystallization of samples does not occur during straining in Bridgman's anvils with different strain degrees.

3. Redistribution of chemical elements between the copper shell and the amorphous sample has not been revealed.

4. During straining of bulk metallic glasses with lamellar crystalline inclusions, fracture of MGs takes place, with tearouts of fragments of the crystalline phase into the copper matrix.

5. Straining in Bridgman's anvils using a copper shell can be used for shape-forming of bulk Ti- and Zr-based metallic glasses.

\section{References}

1. R. O. Ritchie. Nature Materials. 10, 817 (2011).

2. A. Inoue. Acta Mater. 48, 279 (2000). 
3. M. Calin, A. Gebert, A.C. Ghinea, P.F. Gostin, S. Abdi, C. Mickel, J. Eckert. Mat. Sci. Eng. C. 33, 875 (2013).

4. J. Eckert, J. S. Pauly, C. Duhamel. Adv. Eng. Mat. 9(6), 443 (2007).

5. L. Liu, C. L. Qiu, C. Y. Huang, Y. Yu, H. Huang, S. M. Zhang. Intermetallics. 17, 235 (2009).

6. J.-J. Oak, G.-W. Hwang, Y.-H. Park, H. Kimura, S.-Y. Yoon, A. Inoue. J. Biomech. Sci.Eng. 4, 384 (2009).

7. D. C. Hoffman, J.-Y. Suh, A. Wiest, G. Duan, M.-L. Lind, M.D. Demetriou, W. L. Johnson. Nature. 451, 1085 (2008).

8. J. T. Fan, A. Y. Chen, M. W. Fu, J. Lu. Scripta Mat. 61(6), 608 (2009).

9. T. Czeppe, G.F. Korznikova, J. Morgiel, A V Korznikov, N Q Chinh, P Ochin, A Sypień. Journal of Alloys and Compounds. 483, 74 (2009).

10. G. Korznikova, T. Czeppe, A. Korznikov. Rev. Adv. Mater. Sci. 25, 67 (2010).

11. T. Czeppe, A. Sypień, G. Korznikova, A. Korznikov. Solid State Phenomena 186, 104 (2012).

12. T. Czeppe, G. F. Korznikova, A. W. Korznikov, L. LitynskaDobrzynska, Z. Swiatek. Archives of metallurgy and materials. 58(2), 447 (2013).
13. A. Sypien. Archives of metallurgy and materials. 58, 348 (2013).

14. A. Sypień, W. Przybyło, J. Mat. Sci. Tech. 26(1), 31 (2010).

15. A. Sypień, T. Czeppe, G. Garzeł, L. Lityńska-Dobrzyńska, J. Latuch, N. Q. Chinh. ISMANAM 20133P1-03.

16. O.A. Smirnov, M.A. Tsepin,V.V. Begnarski, G. F. Korznikova. Kuznechnoshtampovoye proizvodstvo. 10, 9 (2006). (in Russian)

17. O.A. Smirnov, M.A. Tsepin,V.V. Begnarski, G. F.Korznikova,A. V.Korznikov.Kuznechnoshtampovoye proizvodstvo. 5, 19 (2006). (in Russian)

18. G. Korznikova A. Korznikov. Mat. Sci. Eng. A. 503, 99 (2009).

19. B. A. Grinberg, M. A. Ivanov, V. V. Rybin, A. V. Inozemtsev, O. V. Antonova, O. A. Elkina, A. M. Patselov, S. V. Kuz'min, V. I. Lysak, V. Ye. Kozhevnikov. The Physics of Metals and Metallography. 113(2), 176 (2012). (in Russian) 